\title{
Cardiac Surgery in Germany during 2014: A Report on Behalf of the German Society for Thoracic and Cardiovascular Surgery
}

\author{
Andreas Beckmann ${ }^{1}$ Anne-Kathrin Funkat ${ }^{2}$ Jana Lewandowski ${ }^{1}$ Michael Frie ${ }^{3}$ Markus Ernst ${ }^{4}$
} Khosro Hekmat ${ }^{5}$ Wolfgang Schiller ${ }^{6}$ Jan F. Gummert ${ }^{7}$ Joachim Thomas Cremer ${ }^{4}$

${ }^{1}$ German Society for Thoracic and Cardiovascular Surgery, Langenbeck-Virchow-Haus, Berlin, Germany

${ }^{2}$ Clinic for Cardiac Surgery, Heart Center Leipzig, University of Leipzig, Germany

${ }^{3}$ FOM Hochschule fuer Oekonomie \& Management, Essen, Germany

${ }^{4}$ Clinic for Cardiac and Vascular Surgery, University Kiel, Kiel, Germany

${ }^{5}$ Department of Cardiothoracic Surgery, University of Cologne, Köln, Germany

${ }^{6}$ Clinic for Cardiac Surgery, University of Bonn, Bonn, Germany

${ }^{7}$ Clinic for Thoracic and Cardiovascular Surgery, Heart and Diabetes

Center NRW, Bad Oeynhausen, Germany

Thorac Cardiovasc Surg 2015;63:e1.
Address for correspondence Dr. med. Andreas Beckmann, Deutsche Gesellschaft für Thorax-, Herz- und Gefäßchirurgie [DGTHG], Langenbeck-Virchow-Haus, Luisenstr. 58-59, 10117 Berlin, Germany (e-mail: gf@dgthg.de).

\section{ERRATUM}

The German Society for Thoracic and Cardiovasular Surgery has informed the Editor-inChief that there is a mistake in -Table V1 in the above article in the Thoracic and Cardiovascular Surgeon, published online May 26, 2015 (DOI: 10.1055/s-0035-1551676). The correct - Table $\mathbf{v} \mathbf{1}$ appears below.

This is in addition to the 1st Erratum published online on June 11, 2015 (DOI: 10.1055/s0035-1556566).

Table V1 Isolated valve procedures (categories)

\begin{tabular}{|l|l|l|l|}
\hline Procedures & N & Deaths & $\%$ \\
\hline Single & 18,408 & 625 & 3.4 \\
\hline Double & 3,288 & 314 & 9.5 \\
\hline Triple & 372 & 50 & 13.4 \\
\hline Transcatheter access (single value) & 9,184 & 386 & 4.2 \\
\hline Transcatheter access (double value) & 10 & 1 & 10.0 \\
\hline Not specified & 97 & 8 & 8.2 \\
\hline Total & 31,359 & 1,384 & 4.4 \\
\hline
\end{tabular}

Notes: Combined procedures (with coronary artery bypass grafting, aortic surgery) are excluded. Transcatheter valve procedures: 8,631 aortic valve implantations; 91 mitral valve implantations; 457 mitral valve repairs; 3 tricuspid valve implantations; 2 tricuspidal valve repairs; 10 combined procedures, aortic and mitral valve procedure; no pulmonary valve implantation. 